\title{
Calcitonin gene related peptide (CGRP) in pain and migraine: a mini-review
}

\begin{abstract}
In this mini-review the role of CGRP (Calcitonin Gene-Related Peptide) in pain processing pathways and in migraine are discussed. Physiology and pathophysiology of CGRP in non-headache pain as somatic, visceral, inflammatory and neuropathic pain are evaluated. Results are conflicting and it appears that there are no clinical trials establishing the role of CGRP as a sensory pain modulator in non-headache pain. In contrast, the four new anti-CGRP antibodies developed for the prevention of migraine attacksreduce headache frequency in half of patients by $50 \%$. Safety and tolerability during the 3-months trials appear good but long-term safety is unknown. Expected pricing and the potential market size of $\$ 5$ billion to $\$ 10$ billion are discussed.
\end{abstract}

Volume 6 Issue 2 - 2018

\author{
Michael AB Naafs \\ Endocrinologist, Health Consultant at Naafs, International \\ Health Consultancy, The Netherlands \\ Correspondence: Michael AB Naafs, Dutch Internist, \\ Endocrinologist, Health Consultant at Naafs, International \\ Health Consultancy, Rhodoslaan 20,7577KN, Oldenzaal, The \\ Netherlands, Tel +31681589079, Email \\ naafs.healthconsultancy@gmail.com, \\ michael.naafs@hotmail.com
}

\section{Introduction}

Calcitonin Gene Related Peptide (CGRP) is a 37 amino-acid neuropeptide identified in 1982 by Amara et al. ${ }^{1}$ They found that alternate splicing of the gene for calcitonin (CT) produced a very different peptide designated as alpha-CGRP. Subsequently, a novel gene coding a homologous peptide was discovered. This peptide beta-CGRP differs from alpha-CGRP by a single amino acid in the rat and 3 amino acids in humans. ${ }^{2}$ The biological activity of these 2 forms of CGRP is nearly identical but based on receptor binding assays and in vitro-bioassays there are small differences in potency. ${ }^{2}$ Alpha- and beta CGRP belong to the calcitonin (CT) receptor family of peptides. These also include procalcitonin(proCT), calcitonin (CT), adrenomedullin (AM), amylin (AMY), intermedin (AM2) as well as the carboxy-terminal fragments CGRP(18-37) and CGRP(19-37). These fragments have been found in the spinal cord of the rat; the CGRP(19-37) fragment is an antagonist of the CGRP receptor. ${ }^{3,4}$

The CGRP receptor is atypical among the family of $\mathrm{G}$ proteincoupled receptorsb ecause the functional receptor is composed from the heterodimerization of 2 peptides. ${ }^{5}$ These 2 peptides, the receptor activity-modifying protein 1 (RAMP1) accessory protein and the calcitonin receptor-like receptor (CLR) protein are required to efficiently couple to the Gs unit. ${ }^{5-7}$ Moreover CGRP has affinity to other receptors, including the amylin 1(AMY1) receptor, which is also a heterodimer containing RAMP1 but with the calcitonin receptor (CT) protein..$^{6-8}$ Calcitonin gene related peptide's affinity for AMY1 is comparable with the CGRP receptorand has been proposed as a second CGRP receptor site. ${ }^{9}$ In addition, to its role as a pain modulator in the somatosensory system, CGRP is also an extremely potent vasodilator. Vascular beds, including the mesenteric and meningeal vasculatures, are rich in CGRP receptors. There is evolving evidence, that CGRP plays a critical role in the trigeminovascular origin of the pathogenesis of migraine. ${ }^{10,11}$

In this mini-review the role of CGRP in pain-processing pathways and particularily in migraine are discussed. The recent results of phase 1 and 2 and 3 clinical trials with monoclonal antibodies directed at CGRP, or its receptor, will be evaluated too.

\section{CGRP as a pain modulator in non-headache pain}

CGRP is primarily released from sensory nerves and is involved in pain pathways in this way. It is localized to $\mathrm{C}$ and $\mathrm{A}$, delta sensory fibers of specialized peripheral sensory neurons, known as nocireceptors. Activation of these nocireceptors and the processing of information they convey, provide a rich diversity of pain qualities. ${ }^{12}$ The regulation of CGRP synthesis is still poorly understood. CGRP synthesis is known to be upregulated in models of nerve damage, such as peripheral axotomy, and it is believed that synthesis of the peptide is enhanced in tissuesthat are undergong an inflammatory response. ${ }^{13}$ The realization that CGRP was present in sensory nerves led to studies with the chili extract capsaicin, which is now known to activate transient receptor potential vanilloid 1(TPRV1) receptors, commonly found on sensory $\mathrm{C}$ - and A, delta fibers. Capsaicin has long been known to cause pain and redness on acute application. Thus, its ability to release CGRP and the co-localized neuropeptide substance P was not a surprise. ${ }^{14-16}$

In the periphery, the primary afferent nocireceptors terminate as fine nerve endings, innervating peripheral structures. ${ }^{17}$ Tissue injury results in the release of numerous proinflammatory mediators from the injured cells, mast cells, leukocytes and the nerve terminals. These substances include the tachykinins, bradykinin, prostaglandins, serotonin, histamine, as well as the release of CGRP and substance $\mathrm{P}$ from the nerve endings. ${ }^{17}$ These proinflammatory mediators can directly activate the nocireceptors. Generate action potentials, or facilitate the firing of the nocireceptors, resulting in peripheral sensitization and hyperalgesia. Activation of a free nerve ending can produce an axon reflex action, which causes the release of CGRP and substance $\mathrm{P}$ from adjacent free endings of the same axon, resulting in the release of additional proinflammatory mediators. This in turn can further excite adjacent nerve endings and thus propagate an expanding area of neurogenic inflammation,indicated by the erythematous flare response. ${ }^{17-20}$

\section{CGRP in somatic pain}

Several studies have shown a relationship between CGRP levels 
and somatic pain and pain intensity. ${ }^{21}$ In chronic knee pain, due to osteoarthrosis elevated CGRP levels were detected in serum and synovial fluid in patients $(\mathrm{n}=65)$ compared with controls $(\mathrm{n}=21)$. Serum CGRP levels were positively correlated with pain intensity. ${ }^{21}$ Chronic low back pain patients, due to osteoarthrosis, $(n=32)$, showed decreased CGRP levels four months after acupressure pain treatment compared to baseline. No decrease was found in patients who received sham treatment $(\mathrm{n}=29) .{ }^{22}$ In addition, studies using immunofluorescence of skin biopsies reported decreased CGRP after acupuncture treatment of osteoarthrosis patients $(n=6) \cdot{ }^{23}$ Immunohistochemistry analysis of synovial tissue from fossa acetabuli, showed increased CGRP levels compared to controls $(n=9)^{24}$ and $(n=67),{ }^{25}$ respectively. Another study reported higher levels of CGRP in hip synovium from osteoarthritis patients compared with femoral neck patients $(n=62) .{ }^{26}$ Higher CGRP levels were also found in synovial tissues from temporomandibular joint pain patients compared with controls. This study also reported positive correlations between pain and CGRP levels $(n=55) .{ }^{27}$ Biopsies from knee joint ligaments showed no difference in CGRP nerve density between patients and non-arthrosis. $(n=15) .{ }^{28}$ In patients with osteoarthrosis CGRP concentration in cerebrospinal fluids was decreased compared to controls $(n=35) .{ }^{29}$ In patients suffering from chronic pain due to degenerative disc disease, disc biopsies showed increased CGRP, compared to post-mortem control discs $(\mathrm{n}=22){ }^{30}$ Biopsies from intervertebral discs in patients contained CGRP-IR (immunoreactive) nerve fibers. ${ }^{31}$ Whiplash injury patients and disc herniation patients showed increased blood levels of CGRP. ${ }^{32,33}$

\section{CGRP in visceral pain}

Immunofluorescence based analysis of peritoneal fluid obtained during laparoscopy in patients with endometriosis showed increased CGRP levels compared to peritoneal fluid from controls without endometriosis. ${ }^{34}$ Patients with non-erosive reflux disease and functional dyspepsia were investigated by enzyme-and radioimmunoassay. No differences in CGRP reactivity of mucosal biopsies were found compared to controls. ${ }^{35,36}$ Plasma CGRP levels were studied in patients with suspected or definite myocardial infarction at admission at a coronary care unit. This study revealed no differences in CGRP levels between patients with and without acute myocardial infarction and no difference between patients with pain and those without pain. ${ }^{37}$

\section{CGRP in inflammatory pain}

ELISA or dermal microdialysate from volar forearm studies showed elevated blood CGRP levels in 10 healthy volunteers with capsaicin-induced pain. ${ }^{38}$ No CGRP release was detected via dermal microdialysate after electrical stimulation in the same area. ${ }^{38}$ In contrast,another study found CGRP in the dialysate after histamne iontophoresis but not after capsaicin application in the volar arm. ${ }^{39}$ Immunohistochemical analysis of skin biopsies in patients with painful scars from burns showed ncreased CGRP compared with controls with burn scars without pain. ${ }^{40}$ Moreover, ELISA of peripheral blood showed increased CGRP levels up to 24 hours after burn injuries compared with healthy volunteers ${ }^{41}$ and in patients with pruritis due to atopic dermatitis. ${ }^{42}$ Furthermore, CGRP levels were positively correlated with the severity of pruritis. ${ }^{42}$ Nociceptive fibers have been shown to be involved in the sensation of pruritis. ${ }^{43}$

\section{CGRP in neuropathic pain}

Radioimmunoassay showed higher serum CGRP levels in 19 patients with complex regional pain syndrome (CRPS) compared to controls. The difference was normalized after a 9-month pain management therapy. ${ }^{44}$ In contrast, another study found decreased CGRP levels in chronic CPRS patients $(\mathrm{n}=12)$ compared with healthy controls. ${ }^{45}$ No correlation between pain and CGRP levels was found in either study. ${ }^{44,45}$ In post-herpetic neuralgia increased CGRP expression in the affected skin compared with skin from a contralateral side in the same patient was reported by using immunofluorescence analyses of skin biopsies. ${ }^{46}$ No difference in CGRP expression was found between patients with chronic pain due to nerve injury after hand surgery and controls. ${ }^{47}$ The immunochemistry of peripheral nerve biopsies from patients with Morton's neuroma,which results in neuropathic pain,showed increased amount of CGRP in patients compared with controls. ${ }^{48}$ Attal et al. ${ }^{49}$ investigated 152 patients with persistent neuropathic pain of whom 68 were treated with botulinum toxin A and 66 received placebo. CGRP was analyzed in skin biopsies using ELISA at week 1 and 4 in 23 patients, who received botulinum toxin A and in 17 patients, ho received placebo.No difference between the groups was found.

\section{CGRP antagonists and antibodies and clinical trials}

\section{Non-headache pain}

There are no clinical trials on CGRP antagonists and antibodies for the treatment of non-headache pain by searching Pubmed and Embase, despite 35 years of CGRP research. Search on ClinicalTrial. gov. for current CGRP antagonists and antibodies for the treatment of non-headache pain only yields three studies.

The acute effect of PF-04427429 anti-CGRP monoclonal antibody on attenuation of flare response after capsaicin challenge was studied in a double blind randomized, placebo controlled trial in male healthy volunteers, using EMLA cream as a positive control. However, primary outcome was mean blood perfusion and no pain perceptions were studied. ${ }^{50}$

A phase2 randomized, double blind,placebo controlled trial in patients with mild to moderate osteoarthritis knee pain failed to demonstrate efficacy of LY2951742, monoclonal antibody to CGRP. $^{51,52}$

\section{Cluster headache and migraine}

Recently, there was a lot of attention in the mainstream press,regarding the role of anti-CGRP drugs in the prevention of the migraine attacks. ${ }^{53,54} \mathrm{CGRP}$ is highly prevalent as a neurotransmitter in the trigeminovascular system.CGRP levels are found in high levels during migraine attacks. ${ }^{55}$ Maximum increases in plasma levels of CGRP are reached within 2 hours of the onset of the attacks and can be reverted by treatment with the tryptans.CGRP levels measured in peripheral blood outside migraine attacks and in the absence of symptomatic medication have been shown to be increased in chronic migraine patients. Increased CGRP levels were able to predict the response to onabotulinumtoxin $A$ treatment and were reduced 1 month after onabotulinum type A therapy. ${ }^{55}$ Migraine is primarily a complex disorder involving local vasodilation of intracranial, extracerebral blood vessels and simultaneous stimulation of surrounding trigeminal sensory nervous pain pathways that result in headache.

It is believed that "activation"of the trigeminovascular system causes release of various vasodilators, espescially CGRP, that is 
supposed to induce the pain response although hard evidence is not available. ${ }^{56}$ As depicted above,the relationship between CGRP and pain perception has been documented badly in decades of research in non-headache pain. Nevertheless, the trigeminovascular release of CGRP during a migraine attack is accompanied by decreased levels of the neurotransmitter serotonin. Serotonin agonists as the tryptans (Sumatriptan, Imigran) are vasoconstrictors. They bring the elevated levels of CGRP to normal. Tryptans and the ergot alkaloids have been proven efficacious in the treatment of migraine..$^{57}$ The ergot alkaloids have partial agonist activity at serotonin and are antagonists at adrenergic, tryptaminergic and dopaminergic receptors. Their relationship with CGRP is not well known..$^{55}$ Varying levels of ovarian hormones, especially estrogen, influence the serotonin neurotransmitter system and CGRP levels making women more proposed to migraine attacks. ${ }^{57}$

\section{Migraine prevention and CGRP antibodies}

Prevention is a key component of migraine. While numerous preventive options exist, each is hampered by either troublesome side effects or insufficient efficacy. For that reason CGRP has moved to the forefront as a neuropeptide control to migraine prevention. Six small molecule receptor antagonists were shown to be effective for the acute treatment of migraine. Two were stopped for hepatotoxicity. At present, four CGRP monoclonal antibodies completed phase 2 trials or are in phase 3 trials.$^{58}$ These results will be discussed now.

\section{Galcanezumab (LY 2951427)}

The first phase 2 clinical trial results to be published were for Eli-Lilly's galcanezumab. Patients with episodic migraine (4 to 14 headaches in a 4 week baseline period) were randomized to galcanezumab $150 \mathrm{mg}$ s.c. versus placebo every 2 weeks for 12 weeks. Primary efficacy endpoint was the change in number of migraine headache days (MHDs) during the third 4-week treatment period (weeks 9-12). The mean change in MHDs was significantly different in the galcanezumab group compared to the placebo Group (-4,2 versus-3,0 days; $<<0,003) .{ }^{59}$ Galcanezumab was tested in the REGAIN trial in patients with chronic migraine. At doses of $120 \mathrm{mg}$ s.c per month $(\mathrm{n}=278)$ or $240 \mathrm{mg}$ s.c per month the active drug proved superior to placebo $(\mathrm{n}=558)$. At months 1 to 3 the overall mean change in MHDs was $-2,74$ for placebo,-4,83 for the $120 \mathrm{mg}$ dose and -4.62 for the $240 \mathrm{mg}$ dose ( $<<0,001$ for both doses versus placebo). At baseline all participants had 15 MHDs per month with medication use. Almost twice as many participants in the drug groups $(27 \%)$ experienced a $50 \%$ reduction in monthly MHDs compared with the placebo group $(15,4 \% ; \mathrm{p}<0,001)$. Participants tolerated the active treatment well with few dropouts. Most of the dropouts were in the placebo-group (49 of 558).

The $120 \mathrm{mg}$ s.c. dose was pinpointed as the lowest effective dose in a phase $2 \mathrm{~b}$ study comparing $120 \mathrm{mg}$ versus $300 \mathrm{mg}$ doses $(\mathrm{n}=410)$. Only the $120 \mathrm{mg}$ met the primary objective of "posterior probability of greater improvement" ( Bayeasian analysis) MHDs,than the specified tresholds of $95 \%$ for mean change versus placebo. The posterior probability was $99,6 \%$ for the $120 \mathrm{mg}$ group, which had mean reductions of 4,8 MHDs by week 12 versus reductions of 3,7 MHDs in the placebo group..$^{59}$ Common treatment related adverse effects (AEs) for the galcanezumab group included injection-side pain, upper respiratory tract infections, nasopharyngitis and abdominal pain. ${ }^{60}$ Remember as depicted above,galcanezumab failed in a phase 2 trial in patients with mild to moderate osteoarthritis knee pain. ${ }^{51,52}$ Eli-Lilly has submitted their results,sampled in the REGAIN 7-9, Evolve1 and Evolve2 trials $(\mathrm{n}=2900)$ for FDA approval on December 12th 2017.

\section{Epitinezumab (ALD-403)}

ALD-403 (Alder Biopharmaceuticals) is administered intravenously,aiming at a direct physiological effect with rapidly efficacious dosing.Patients with episodic migraine (5-14 MHDs per month) were randomized to either a single dose of monthly $1000 \mathrm{mg}$ or placebo. The primary endpoint was the change in number of MHDs during weeks 5 to 8 compared to the baseline period. Epitinuzemab resulted in significantly fewer migraine days compared to placebo $(-5,6$ vs-4,6 days, respectively; $\mathrm{p}<0,03){ }^{61}$

\section{Fremanezumab (TEV-48215 or LBR-101)}

Teva Pharmaceuticals investigated fremanezumab in two trials. One for patients with high-frequency migraine and the other for patients with chronic migraine. ${ }^{62,63}$ Patients with 8-14 MHDs in a 4 week baseline period were randomized to subcutaneous injections of either $225 \mathrm{mg}$ or $675 \mathrm{mg}$ or placebo every 4 weeks for 12 weeks. Primary endpoint was the change in number of MHDs during the third 4 week-treatment period (weeks 9-12) compared to the baseline period. The reduction in MHDs was significantly greater for both the fremanezumab $225 \mathrm{mg}(-6,27$ vs 3,46 days; $p<0,001)$ and 675 $\mathrm{mg}$ doses $(-6,09 \mathrm{vs}-3,46$ days; $\mathrm{p}<0,001)$. Of note, in contrast to the previous two studies, patients were not excluded for a migraine preventive,provided the dose was stable for 2 months before screening. In the chronic migraine trial, patients were randomized to either placebo or one of two fremanezumab doses given every 4 weeks for 12 weeks; $675 \mathrm{mg}$ loading dose,followed by two $225 \mathrm{mg}$ doses or three doses of $900 \mathrm{mg}$. Primary endpoint was change in hours of headache of any severity during the third 4-week treatment period (weeks 9-12) compared to the baseline period. Mean reduction in headache hours of any severity was significantly greater compared to placebo for both the fremanezumab $675 \mathrm{mg} / 225 / 225 \mathrm{mg}(-59,8 \mathrm{vs}-$ $37,1$ hour; $p=0,03)$ and $900 \mathrm{mg}$ doses $(-67,5$ vs-37, 1 hour; $p=0,005)$. Use of up to two preventives was permitted,provided the doses were were stable for at least 3 months before the start of the study.

\section{Erunumab (AMG-334)}

While galcanezumab, epitinezumab and fremanezumab are CGRP monoclonal antibodies, AMG-334(Amgen) or erenumab is the only CGRP receptor monoclonal antibody up until now. Patients with episodic migraine (4-14 MHDs in a 4-week baseline period) were randomized to either placebo or one of three doses of erenumab $(7,14$,or $70 \mathrm{mg})$ s.c every 4 weeks for 12 weeks. Primary endpoint was the change in number of MHDs during the third 4-week treatment period. Mean change in MHDs was significantly different from the placebo-group, only for the highest dose, erenumab $70 \mathrm{mg} \mathrm{(-3,4} \mathrm{vs}$ $2,3$ days; $p=0,02) \cdot{ }^{64}$

\section{Pharmacology evaluation of the CGRP antibodies}

Initial safety and tolerability for the anti-CGRP monoclonal antibodies appears good. ${ }^{60-64}$ Immunogenecity by inducing ant-drug antibodies is not a problem during all of these 3-months trials, so far. As all the CGRP monoclonal antibodies have a long biological half-life of 31 days, the long-term safety is entirely unknown at this time. CGRP has a complex physiological function than but merely of 
a sensory pain modulator. CGRP receptors are found in the nervous, vascular system, adrenals, kidneys, pancreas and bone. The effects of chronic CGRP antagonism on these organs are not known. Since the CGRP antibodies have a very long biological half-life any untoward effects can not be reversed quickly. ${ }^{58}$ Though developed by four different companies, he preventive drugs are fairly similar. They are injected once a month and seem to reduce headache frequency in half of patients by $50 \%$. An oral CGRP antagonist developed by Allergan, atogepant, is in mid-stage clinical trials. The first CGRP preventive migraine drug might come on the market mid-2018. Pricing is expected to start at $\$ 8,500$ a year, comparable to the pricing of the cholesterol-controlling PCSK9 inhibitors. About seven million patients would likely get the treatment resulting in a $\$ 5$ billion to $\$ 10$ billion potential market size. ${ }^{65}$

\section{Discussion}

A review of the role of CGRP as a sensory pain modulator yields conflicting results in somatic, visceral, inflammatory and neuropathic pain. It appears there are no clinical trials establishing the role of CGRP as a sensory pain modulator in non-headache pain despite 35 years of research. However, the new anti=CGRP monoclonal antibodies developed for the prevention of migraine show highly concordant results. All of these 4 Anti-CGPR antibodies reduce headache frequency in half of patients by $50 \%$. This is rather surprising compared to the results in non-headache pain. So far,this is not explained, but it suggests different mechanisms in pain perception in migraine and non-headache pain. Short-time safety and tolerability of the anti-CGRP antibodies appear good but long-term safety is unknown. The filing for FDA approval by four different pharmaceutical companies looks like a race against the clock for pole position in a $\$ 5$ billion to $\$ 10$ billion market.

\section{Aknowledgment}

None.

\section{Conflict of interets}

None.

\section{References}

1. Amara SG, Jonas V, Rosenfeld MG, et al. Alternative RNA processing in calcitonin gene expression generates mRNAs encoding different polypeptide products. Nature. 1982;298:240-244.

2. Amara SG, Arizza JL, Leff SE, et al. Expression in brain of a messenger RNA encoding a novel neuropeptide homologous to calcitonin gene related peptide. Science. 1985;229:1094-1097.

3. Asghar MS, Becerra L, Larsson HB, et al. Calcitonin gene-related peptide modulates heat nociception in the human brain: an fMRI study in healthy volunteers. Plos One. 2016;11(3):e0150334.

4. Becker KL, Nylen ES, White JC, et al. Clinical review 167: procalcitonin and the calcitonin gene family of peptides in inflammation, infection and sepsis: a journey from calcitonin back to its precursors. J Clin Endocrinol Metab. 2004;89(4):1512-1525.

5. Rusell FA, King R, Smillie SJ, et al. Calcitonin gene related peptide physiology and pathophysiology. Physiol Rev. 2014;94(4):1099-1142.

6. Poyner DR, Sexton PM, Marshall I, et al. International Union of Pharmacology 32. The mammalian calcitonin gene-related peptides, adrenomedullin,amylin and calcitonin receptors. Pharmacol Rev. 2002;54(2):233-246.

7. Russo AF, Dickerson IM. CGRP: a multifunctional neuropeptide. In: Lajtha A, Lim R, editors. Handbook of neurochemistry and molecular neurobiology: neuroactive proteins and peptides. Boston, Springer; 2006: 391-426.

8. Wimalawansa SJ. Calcitonin gene-related peptide and its receptors: molecular genetics, physiology, pathophysiology and therapeutic potentials. Endocr Rev. 1996;17(5):533-585.

9. Walker CS, Eftekhari S, Bower RL, et al. A second trigeminal CGRP receptor; function and expression of the AMY1 receptor. Ann Clin Transl Neurol. 2015;2(6):595-608.

10. Edvinsson L. CGRP receptor antagonists and antibodies against CGRP and its receptor in migraine treatment. Br J Clin Pharmacol. 2015;80(2):193199 .

11. Miller S, Liu H, Warfinge $\mathrm{K}$, et al. Immunohistochemical localization of the calcitonin gene-related peptide binding site in the primate trigeminovascular system using functional antagonist antibodies. Neuroscience. 2016;328:165-183.

12. Dubin AE, Patapoutian A. Nociceptors: the sensors of the pain pathway. $J$ Clin Invest. 2010;120(11):3760-3772.

13. Donnerer J, Stein C. Evidence for an increase in the release of CGRP from sensory nerves during inflammation. Ann NY Acad Sci. 1992;657:505-506.

14. Gibbins IL, Furness JB, Costa M, et al. Co-localization of calcitonin gene-related peptide-like immunoreactivity with substance $\mathrm{P}$ in cutaneous,vascular and visceral sensory neurons of guinea pigs. Neurosci Lett. 1985;57(2):125-130.

15. Lundberg JM, Franco-Cerceda A, Hua X, et al. Co-existence of substance $\mathrm{P}$ and calcitonin gene related peptide-like immunoreactivities in sensory nerves in relation to cardiovascular and bronchoconstrictor effects of capsaicin. Eur J Pharmacol. 1985;108(3):315-319.

16. Zaidi M, Bevis PJ, Girgis SI, et al. Circulating CGRP comes from the perivascular nerves. Eur J Pharmacol. 1985;117(2):283-284.

17. Basbaum AL, Bautista DM, Scherrer G, et al. Cellular and molecular mechanisms of pain. Cell. 2009;139(2):267-284.

18. Holta H, Sato A, Sato Y, et al. Stimulation of saphenous afferent nerve produces vasodilatation of the vasa nervorum via an axon reflex-like mechanism in the sciatic nerve of anesthetized rats. Neurosci Res. 1996;24(3):305-308

19. Sann H, Pirau FK. Efferent functions of $\mathrm{C}$-fiber nocireceptors. $Z$ Rheumatol. 1998;57(Suppl 2):8-13.

20. Schmelz M, Luz O, Averbeck B, et al. Plasma extravasation and neuropeptide release in human skin as measured by intradermal microdialysis. Neurosci Lett. 1997;230(2):117-120.

21. Dong T, Chang H, Zhang F, et al. Calcitonin gene-related peptide can be selected as a predictive biomarker on progression and prognosis of knee osteoarthritis. Int Orthop. 2015;39(6):1237-1243.

22. Lin WC, Yeh $\mathrm{CH}$, Chien LC, et al. The anti-inflammatory actions of auricular point acupressure to chronic low back pain. Evid Based Complement Alternat Med. 2015; 9 p.

23. Carlsson CP, Sandler F, Wallengren J, et al. Cutaneous innervation before and after one treatment period of acupuncture. $\mathrm{Br} J$ Dermatol. 2006;155(5):970-976.

24. Saxler G, Löer F, Skumavic M, et al. Localization of SP-and CGRP immunopositive nerve fibers in the hip joint of patients with painful 
osteoarthritis and of patients with painless failed total hip arthroplasties. Eur J Pain. 2007;11(1):67-74.

25. Wang H, Zhang X, He JY, et al. Increasing expression of substance P and calcitonin gene-related peptide in synovial tissue and fluid contribute to the progress of arthritis in developmental dysplasia of the hip. Arthritis Res Ther. 2015;17:4.

26. Takeshita M, Nakamura J, Ohtari S, et al. Sensory innervation and inflammatory cytokines in hypertrophic synovia associated with pain transmission in osteoarthritis of the hip:a case control-study. Rheumatology, Oxford. 2012;51(10):1790-1795.

27. Sato J, Segami N, Kaneyama K, et al. Relationship of calcitonin gene-related peptide in synoval tissues and temperomandibular joint pain in humans. Oral Surg Oral Med Oral Pathol Oral Radiol Endod. 2004;98(5):533-540.

28. Ikeuchi M, Wang Q, Izumi M, et al. Nociceptive sensory innervation of the posterior cruciate ligament in osteoarthritic knees. Arch Orthop Trauma Surg. 2012;132(6):891-895.

29. Lindh C, Liu Z, Welin M, et al. Low calcitonin gene-related peptidelike immunoreactivity in cerebrospinal fluid from chronic pain patients. Neuropeptides. 1999;33(6):517-521.

30. Brown MF, Hukkhanen MV, McCarthy ID, et al. Sensory and sympathetic innervation of the vertebral endplate in patients with degenerative disc disease. J Bone Joint Surg. 1997;79(1):147-153.

31. Ozawa T, Ohtori S, Inoue G, et al. The degenerative lumbar intervertebral disc is innervated by peptide-containing sensory nerve fibers in humans. Spine. 1976;31(21):2418-2422.

32. Alpar EK, Onuaho G, Killampalli VV, et al. Management of chronic pain in whiplash injury. J Bone Joint Surg. 2002;84(6):807-811.

33. Takeuchi H, Kawaguchi S, Ohwado O, et al. Plasma neuropeptides in patients undergoing lumbar discectomy. Spine. 2007;32(2):E79-E84.

34. Barcena de Arrellana ML, Arnold J, Vercillino GF, et al. Influence of nerve growth factor in endometriosis-associated symptoms. Reprod Sci. 2011;16(12):1202-1210.

35. Yoshida N, Kuroda M,Suziki T, et al. Role of nocireceptors/neuropeptides in the pathogenesis of visceral hypersensitivity of nonerosive reflux disease. Dig Dis Sci. 2013;58(8):2237-2243.

36. Monnikes H, Van der Voort IR, Wollenberg B, et al. Gastric perception tresholds are low and sensory neuropeptide levels high in helocobacter pylori-positive functional dyspepsia. Digestion. 2005;71(2):111-123.

37. Währborg P, Eliasson T, Edvarsson H, et al. Acute ischemic chest pain is not associated with increased calcitonin gene-related peptide(CGRP) levels in peripheral plasma nor in the coronary circulation. Scand Cardiovasc J. 1999;33:295-299.

38. Geber C, Fondel R, Kramer HH, et al. Psychophysics,flare and neurosecretory function in human pain models:capsaicin versus electrically evoked pain. J Pain. 2007;8(6):503-514.

39. Schmelz M, Luz O, Averbeck B, et al. Plasma extravasation and neuropeptide release in human skin as measured by intradermal microdialysis. Neurosci Lett. 1997;230(2):117-120.

40. Hamed K, Giles N,Anderson J, et al. Changes in cutaneous innervation in patients with chronic pain after burns. Burns. 2011;37(4):631-637.

41. Onuoha GN, Alpar EK. Levels of vasodilators (SP,CGRP) and vasoconstrictor (NPY) peptides in early human burns. Eur J Clin Invest. 2001;31(3):253-257.

42. Salomon J, Baran E. The role of selected neuropeptides in the pathogenesis of atopic dermatitis. J Eur Acad Dermatol Venerol. 2008;22(2):223-228.
43. Ringkamp M, Schepers RJ, Shimada SG, et al. A role for nociceptive myelinated nerve fibres in itch sensation. J Neurosci. 2011;31(42):1484114849.

44. Birklein F, Schmelz M, Schifter S, et al. The important role of neuropeptides in complex regional pain syndrome. Neurology 2001;57(12):2179-2184.

45. Schinkel C, Scherens A, Köller M, et al. Systemic inflammatory mediators in post traumatic complex regional pain syndrome (CPRS): longitudinal investigations and differences to control groups. Eur J Med Res. 2009:14(3):130-135.

46. Hou Q, Bart T, Gee L, et al. Keratinocyte expression of calcitonin generelated peptide beta: implications for neuropathic and inflammation pain mechanisms. Pain. 2011;152(9):2036-2051.

47. Kallomäki M, Kiesentzky JV, Schmidt R, et al. Structural and functional differences between neuropathy with and without pain? Exp Neurol. 2011;231:199-206.

48. Lindqvist A, Rivero-Melian C, Turan I, et al. Neuropeptide-and tyrosine hydroxylase-immunoreactive nerve fibers in painful Morton's neuromas. Muscle Nerve. 2000;23(8):1214-1218.

49. Attal N, de Andrade DC, Adam F, et al. Safety and efficacy of repeated injections of botulinum toxin $\mathrm{A}$ in peripheral neuropathic pain (BOTNEP):A randomized double blind,placebo-controlled trial. Lancet Neurol. 2016;15(6):555-565.

50. Pfizer S. Acute Response Capsaicin Flare Study in Clinical Trials.gov. National Library of Medicine; 2011.

51. Eli Lilly. Company: A study of LY 2951742 in Participants With Mild to Moderate Osteoarthritis Knee Pain. In: ClinicalTrials.gov, Bethesda (MD), National Library of Medicine. US

52. Jim Y, Smith C, Monteith D, et al. LY 2951742, a monoclonal antibody against CGRP failed to reduce signs and symptoms of knee osteoarthritis. Osteoarthritis Cartilage. 2016;24(1):S50.

53. Rockoff JD. New Migraine Drugs Are On the Horizon. Wall Street Journal; 2016.

54. Parminder D. New drugs May Stop Migraines Before They Start. NBC News Health; 2017.

55. Ramon C, Cemuda-Morollion E, Pascual J. Calcitonin gene-related peptide in peripheral blood as a biomarker for migraine. Curr Opin Neurol. 2017;30(3):281-286.

56. Eftekhari S, Edvinsson L. Possible sites of action of the new calcitonin gene-related peptide receptor antagonists. Ther Adv Neurol Disord. 2010;3(6):369-378.

57. Aggenwol M, Puri V, Puri S. Serotonin and CGRP in Migraine. Ann Neurosci. 2012;19(2):88-94.

58. Tso AR, Goadsby PJ. Anti-CGRP Monoclonal Antibodies; The Next Era of Migraine Prevention? Curr Treat Options Neurol. 2017;19(8):27.

59. Dodick DW, Goadsby PJ, Spierings EL, et al. CGRP monoclonal antibody LY 2951742 for the prevention of migraine: a phase 2 randomized doubleblind placebo-controlled study. Lancet Neurol. 2014;13(9):885-892.

60. Skljarevski V, Oakes TM, Zhang Q, et al. Effect of Different Doses of Galcenezumab vs Placebo for Episodic Migraine Prevention: A Randomized Clinical Trial. JAMA Neurol. 2018;75(2):187-193.

61. Dodick DW, Goadsby PJ, Silberstein SD, et al. Randomized,double blind placebo-controlled,phase 2 trial of ALD 403,an anti CGRP antibody in the prevention of frequent episodic migraine. Lancet Neurol. 2014;13(11):1100-1107.

62. Bugal ME, Dodick DW, Rapaport AM, et al. Safety, tolerability and efficacy of TEV-48125 for preventive treatment of high-frequency episodic 
migraine: a multicentre, randomized, double blind, placebo controlled, phase2b study. Lancet Neurol. 2015;14(11):1081-1090.

63. Bugal ME, Edvinsson L, Rapaport AM, et al. Safety,tolerability and efficacy of TEV-48125 for preventive treatment of chronic migraine; a multicentre, randomized,double-blind, placebo-controlled phase $2 \mathrm{~b}$ study. Lancet Neurol. 2015;14(11):1091-1100.
64. Sun H, Dodick DW, Silberstein S, et al. A randomized,doubleblind,placebo-controlled phase 2 study to evaluate the efficacy and safety of AMG-334 for the prevention of episodic migraine. Lancet Neurol. 2016;15(4):382-390.

65. Court E. New migraine drugs have promise- and a $\$ 8,500$ price tag. Market Watch; 2017. 